\title{
Evaluating the complexity of online patient education materials about brain aneurysms published by major academic institutions
}

\author{
Raghav Gupta, ${ }^{1}$ Nimer Adeeb, MD, ${ }^{1}$ Christoph J. Griessenauer, MD, ${ }^{1}$ Justin M. Moore, MD, PhD, ${ }^{1}$ \\ Apar S. Patel, MD, MPH, ${ }^{1}$ Christopher Kim, ${ }^{2}$ Ajith J. Thomas, MD, ${ }^{1}$ and Christopher S. Ogilvy, MD' \\ 1Department of Surgery, Division of Neurosurgery, Beth Israel Deaconess Medical Center, Harvard Medical School, Boston, \\ Massachusetts; and 2Rutgers New Jersey Medical School, Newark, New Jersey
}

\begin{abstract}
OBJECTIVE Health care education resources are increasingly available on the Internet. A majority of people reference these resources at one point or another. A threshold literacy level is needed to comprehend the information presented within these materials. A key component of health literacy is the readability of educational resources. The National Institutes of Health $(\mathrm{NIH})$ and the American Medical Association have recommended that patient education materials be written between a 4th- and a 6th-grade education level. The authors assessed the readability of online patient education materials about brain aneurysms that have been published by several academic institutions across the US.
\end{abstract}

METHODS Online patient education materials about brain aneurysms were downloaded from the websites of 20 academic institutions. The materials were assessed via 8 readability scales using Readability Studio software (Oleander Software Solutions), and then were statistically analyzed.

RESULTS None of the patient education materials were written at or below the NIH's recommended 6th-grade reading level. The average educational level required to comprehend the texts across all institutions, as assessed by 7 of the readability scales, was $12.4 \pm 2.5$ (mean $\pm \mathrm{SD}$ ). The Flesch Reading Ease Scale classified the materials as "difficult" to understand, correlating with a college-level education or higher. An ANOVA test found that there were no significant differences in readability among the materials from the institutions $(p=0.215)$.

CONCLUSIONS Brain aneurysms affect $3.2 \%$ of adults 50 years or older across the world and can cause significant patient anxiety and uncertainty. Current patient education materials are not written at or below the NIH's recommended 4th- to 6th-grade education level.

https://thejns.org/doi/abs/10.3171/2016.5.JNS16793

KEY WORDS cerebral aneurysm; readability; patient education materials; health literacy; vascular disorders

$\mathrm{T}$ THE Internet has become an indispensable tool for the distribution of information across sociocultural divides. Recent data obtained in 2010 found that nearly $25 \%$ of users have viewed a video pertaining to health or medical issues in the past, and $80 \%$ of users have searched for information regarding specific diseases or treatments online. The Internet serves as an essential medium for the dissemination of patient education materials. ${ }^{19}$ Although this trend would suggest an increasing understanding of medical conditions and their underlying causes among the lay community, such changes have yet to be actualized. In fact, at least 80 million Americans have low health literacy, which results in a staggering economic cost of nearly $\$ 75$ billion annually. ${ }^{6,9}$

The term "health literacy" refers to an individual's ability to comprehend the basic health information needed to make appropriate decisions and use the appropriate services. ${ }^{15} \mathrm{~A}$ key limitation to obtaining health literacy is the poor readability of the educational materials currently available online across a range of medical specialties, including in neurosurgery. ${ }^{3,4,11,14,17,23,25,31,33,35,36}$ Readability is inexorably linked to comprehensibility. Incomprehensibil- 
ity of the existing literature coupled with a hesitance to admit one's low reading level can render a patient vulnerable. ${ }^{29}$ This is particularly concerning given that patients with lower functional reading levels present more frequently with worse health status. ${ }^{27}$ Within the US general population, the average reading level has been found to be that of a 7th- or 8th-grade student, prompting the National Institutes of Health (NIH) and the American Medical Association (AMA) to recommend that patient education materials be written at a reading level no higher than the 6th grade. ${ }^{38}$ An increase in the use of magnetic resonance angiography and computed tomography angiography has resulted in a spike in the rate of aneurysm detection. ${ }^{5}$ In this study we assessed the readability of online patient education materials about brain aneurysms that had been published by academic institutions.

\section{Methods}

A Google search was performed in 2016 using the key term "brain aneurysm." Cerebrovascular education materials were downloaded from the websites of the first 20 academic institutions listed. The text was reformatted using word-processing software (Microsoft Word, Microsoft Corp.) to exclude any navigational cues, hyperlinks, references, and images. A readability analysis software, Readability Studio (Oleander Software Solutions Ltd.), was used to assess the readability of the educational materials, using a series of 8 established scales: Coleman-Liau, Flesch-Kincaid, FORCAST, Fry, Gunning Fog, Raygor Estimate, Simple Measure of Gobbledygook (SMOG), and Flesch Reading Ease (Table 1). ${ }^{10,13,21,22,26,28,34}$ SPSS version 21.0 (IBM Corp.) was used to perform statistical analyses. The Kruskal-Wallis H test (1-way ANOVA) was used to compare the average readability scores across the various scales and websites. Statistical significance was defined by a $\mathrm{p}$ value $<0.05$.

\section{Results}

\section{Collection of Patient Education Materials}

Seventeen $(85 \%)$ of the 20 websites had educational materials pertinent to brain aneurysms that were targeted toward patients and were incorporated into the statistical analysis.

\section{Readability Analysis}

The average grade level at which the patient education materials were written was evaluated using the ColemanLiau, Flesch-Kincaid, FORCAST, Fry, Gunning Fog, Raygor Estimate, and SMOG readability assessment scales ${ }^{10,13}$, $21,22,26,28,34$; according to these scales the grade levels were $12.8 \pm 1.6,11.2 \pm 2.2,11.3 \pm 1.1,12.9 \pm 3.8,13.7 \pm 1.9,11.2$ \pm 5.0 , and $13.5 \pm 1.9$, respectively (Fig. 1). The scores are expressed as the mean \pm SD. An average of all readability scores indicated that the materials were written at a mean grade level of $12.4 \pm 2.5$ (Table 2). Materials published online by the University of California, Los Angeles, required the highest level of education to read (mean grade level 15.9), whereas those written by the University of Pittsburgh needed the lowest (mean grade level 10.0). Using
TABLE 1. Readability assessment scales

\begin{tabular}{ll}
\multicolumn{1}{c}{$\begin{array}{c}\text { Readability } \\
\text { Assessment Scale }\end{array}$} & \multicolumn{1}{c}{ Algorithm* } \\
\hline Coleman-Liau & $((0.0588 \times \mathrm{A})-(0.296 \times \mathrm{B}))-15.8$ \\
\hline Flesch-Kincaid & $(0.39 \times \mathrm{C})+(11.8 \times \mathrm{D})-15.59$ \\
\hline FORCAST & $20-(\mathrm{E} \div 10)$ \\
\hline Fry & 100 -word passage selected from text \\
& No. of sentences w/in passage calculated \\
& No. of syllables w/in passage calculated \\
& Readability calculated using these variables \\
\hline Gunning Fog & $0.4 \times((\mathrm{D} \div \mathrm{F})+100(\mathrm{G} \div \mathrm{D}))$ \\
\hline Raygor Estimate & 100 -word passage selected from text \\
& No. of sentences w/in passage calculated \\
& No. of words w/ $\geq 6$ letters calculated \\
& Readability calculated using these variables \\
\hline SMOG & $1.043 \times \sqrt{ }(\mathrm{H} \times(30 / \mathrm{F}))+3.1291$ \\
\hline Flesch Reading Ease & $206.835-((1.015 \times \mathrm{C})-(84.6 \times \mathrm{D}))$ \\
\hline
\end{tabular}

* The letters designate the following: $A=$ average number of letters per 100 words; $B=$ average number of sentences per 100 words; $C=$ number of "easy" words within sample; $D=$ average number of words per sentence; $E$ = number of single-syllable words in a 150-word sample; $F=$ average number of sentences; $\mathrm{G}=$ average number of words with 3 or more syllables; $\mathrm{H}=$ number of polysyllabic words in sample.

the Flesch Reading Ease scale, ${ }^{26}$ which is scored based on a possible 100 points (with lower numbers denoting more complex texts), we found that materials from all sources were "difficult" to read and required a mid-college-level education or higher (mean score $45 \pm 12$ ). There is a considerable range of scores across individual institutions, with the University of Pittsburgh's patient education materials rated as the easiest to read (mean score 62). Aneurysm education materials published by the University of California, Los Angeles, and Mount Sinai, however, were the most difficult (mean score 22). The differences in average readability scores from individual institutions, across all readability assessment scales, were not statistically significant $(\mathrm{p}=0.215)$.

\section{Discussion}

Analysis of the readability of patient education materials began nearly 4 decades ago with the evaluation of public health messages disseminated by prominent magazines including Readers' Digest, TIME, and Newsweek. ${ }^{20,24}$ The Internet has evolved to become a powerful tool for communication and has enabled patients to access a wealth of health care material. In theory, such changes would produce a more informed public. The material is typically designed to provide patients with a better understanding of diagnoses, symptomatology, treatment options, rehabilitation, and recovery. ${ }^{33}$ In fact, health literacy has been touted as the single best predictor of health care status. ${ }^{7,8}$

Health literacy, however, involves obtaining and interpreting basic health information, and using this information to improve health care. ${ }^{6,37}$ The ease with which a text can be read and understood, referred to as its readability, is directly related to literacy and comprehension. The Nation- 
20

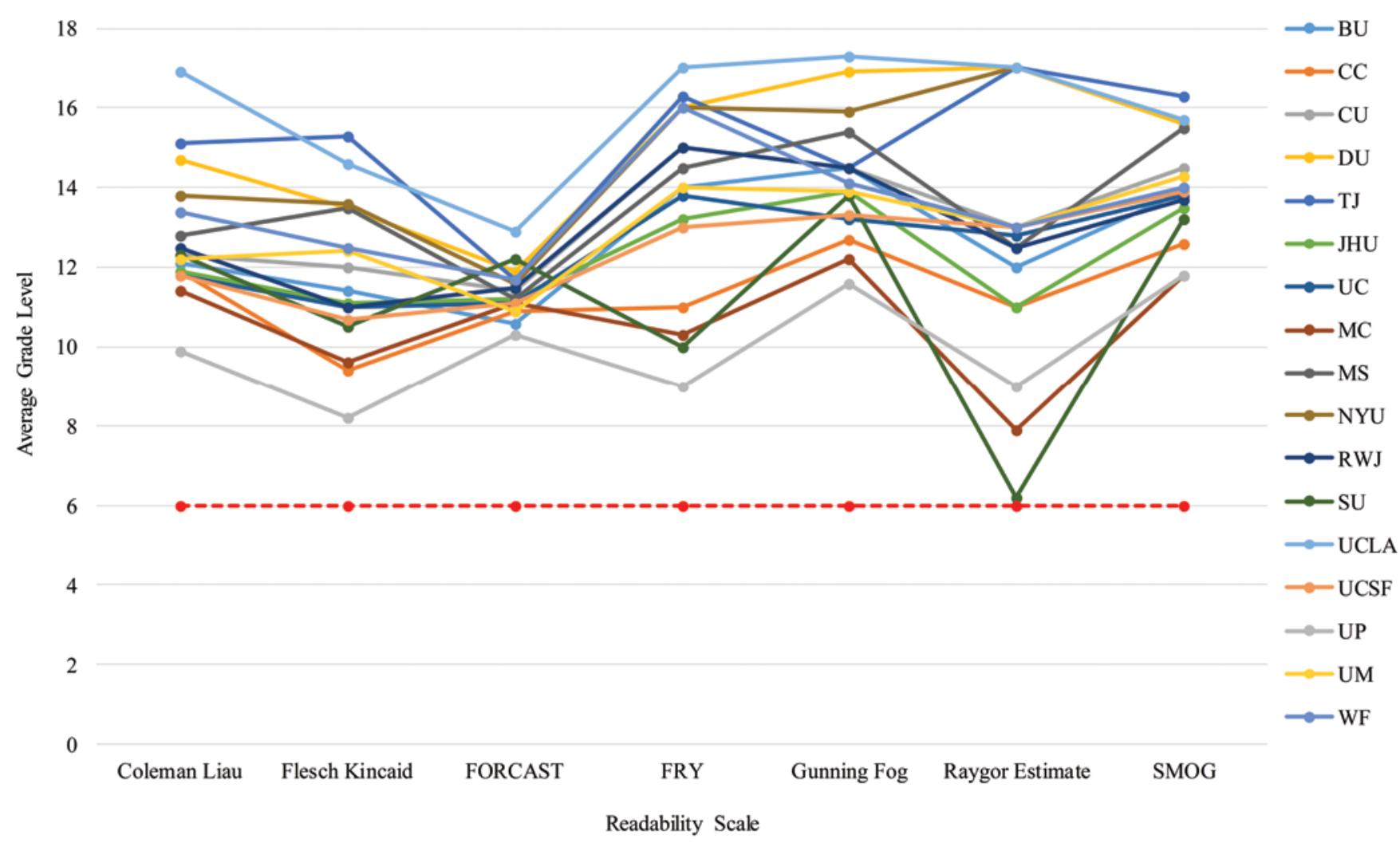

FIG. 1. Graph showing comparison of mean readability scores across institutions. Institutions: $B U=$ Boston University; $C C=$ Cleveland Clinic; $\mathrm{CU}=$ Columbia University; DU = Duke University; $\mathrm{TJ}=$ Thomas Jefferson University; JHU = Johns Hopkins University; UC = University of Cincinnati; MC = Mayo Clinic; MS = Mount Sinai; NYU = New York University/Langone Medical; RWJ = Rutgers Robert Wood Johnson Medical; SU = Stanford University; UCLA = University of California, Los Angeles; UCSF = University of California San Francisco; UP = University of Pittsburgh; UM = University of Michigan; WF = Wake Forest/Baptist Health. Figure is available in color online only.

al Adult Literacy Surveys found that nearly half of the US population can be classified into 2 categories: functionally illiterate and marginally literate. The first category refers to being able to read at a 5 th-grade level or below, whereas the second refers to being able to read at a level between the 6 th and the 8 th grade. ${ }^{6}$ Considering the fact that functional illiteracy is prevalent within pockets of poverty and lower socioeconomic status, health care education materials may be incomprehensible for many patients. It can be argued that the use of the Internet is probably predominant among more highly educated and wealthier members of the public, and the fact that these are the people who are more likely to be accessing the materials, mitigates the effects of complex texts on comprehension. A recent analysis would seem to support this theory, in finding that those with a higher level of educational attainment and/or greater affluence are more likely to adopt the use of this medium..$^{32}$ However, Internet penetration has been rising consistently over the past decade and a half within lowerincome households and among less-educated individuals.

The results from this study indicate that almost all patient education materials related to brain aneurysms are written significantly above the NIH- and AMA-recommended 6th-grade level. In fact, the readability assess- ments indicate that, on average, a 12th-grade education or higher would be needed to comprehend these materials. This would imply a required education level of twice what is recommended by the NIH. Most importantly, none of the institutions published materials at or below the 6thgrade level.

For a preliminary assessment of the readability of brain aneurysm-related patient education resources disseminated in pamphlet form, materials published by the Brain Aneurysm Foundation were evaluated. This foundation is one of the nation's largest nonprofit organizations dedicated to brain aneurysm research and education. The tests indicated that, on average, these materials were written at or above the 12th-grade reading level (mean 12.3), corroborating the results obtained from online patient education materials. This further supported our finding that all patients, including those with and without access to the Internet, are affected by current health education resources. Given the significant anxiety and uncertainty that is associated with brain aneurysms, ${ }^{30}$ it is especially important that online patient education materials are adapted so that they are easily understandable by the lay community. Furthermore, many of these educational materials discuss modifiable risk factors (such as smoking), and if the warn- 
TABLE 2. Readability scores of online patient education materials for brain aneurysms, by institution

\begin{tabular}{|c|c|c|c|c|c|c|c|c|c|}
\hline Academic Institution & $\begin{array}{l}\text { Coleman- } \\
\text { Liau }\end{array}$ & $\begin{array}{l}\text { Flesch- } \\
\text { Kincaid }\end{array}$ & FORCAST & Fry & $\begin{array}{l}\text { Gunning } \\
\text { Fog }\end{array}$ & $\begin{array}{l}\text { Raygor } \\
\text { Estimate }\end{array}$ & SMOG & Mean & $\begin{array}{c}\text { Flesch Reading } \\
\text { Ease }\end{array}$ \\
\hline Boston University & 12.1 & 11.4 & 10.6 & 14.0 & 14.5 & 12.0 & 13.9 & 12.6 & 47 \\
\hline Cleveland Clinic & 11.9 & 9.4 & 10.9 & 11.0 & 12.7 & 11.0 & 12.6 & 11.4 & 54 \\
\hline Columbia University & 12.3 & 12.0 & 11.4 & 15.0 & 14.5 & 13.0 & 14.5 & 13.2 & 42 \\
\hline Duke University & 14.7 & 13.5 & 11.9 & 16.0 & 16.9 & 17.0 & 15.6 & 15.1 & 36 \\
\hline Thomas Jefferson University & 15.1 & 15.3 & 11.7 & 16.3 & 14.5 & 17.0 & 16.3 & 15.2 & 30 \\
\hline Johns Hopkins University & 11.9 & 11.1 & 11.2 & 13.2 & 13.9 & 11.1 & 13.5 & 12.5 & 47 \\
\hline University of Cincinnati & 11.8 & 11.0 & 11.1 & 13.8 & 13.2 & 12.8 & 13.8 & 12.5 & 45 \\
\hline Mayo Clinic & 11.4 & 9.6 & 11.1 & 10.3 & 12.2 & 7.9 & 11.8 & 11.3 & 53 \\
\hline Mount Sinai & 12.8 & 13.5 & 11.2 & 14.5 & 15.4 & 12.5 & 15.5 & 13.6 & 22 \\
\hline NYU/Langone & 13.8 & 13.6 & 11.6 & 16.0 & 15.9 & 17.0 & 15.7 & 14.8 & 35 \\
\hline Rutgers RWJ & 12.5 & 11.0 & 11.5 & 15.0 & 14.5 & 12.5 & 13.7 & 12.9 & 40 \\
\hline Stanford University & 12.3 & 10.5 & 12.2 & 10.0 & 13.8 & 6.2 & 13.2 & 12.3 & 46 \\
\hline UCLA & 16.9 & 14.6 & 12.9 & 17.0 & 17.3 & 17.0 & 15.7 & 15.9 & 22 \\
\hline UCSF & 11.8 & 10.7 & 11.1 & 13.0 & 13.3 & 13.0 & 13.9 & 12.4 & 49 \\
\hline University of Pittsburgh & 9.9 & 8.2 & 10.3 & 9.0 & 11.6 & 9.0 & 11.8 & 10.0 & 62 \\
\hline University of Michigan & 12.2 & 12.4 & 10.9 & 14.0 & 13.9 & 13.0 & 14.3 & 13.0 & 43 \\
\hline Wake Forest Baptist Health & 13.4 & 12.5 & 11.7 & 16.0 & 14.1 & 13.0 & 14.0 & 13.5 & 38 \\
\hline Mean & 12.8 & 11.2 & 11.3 & 12.9 & 13.7 & 11.2 & 13.5 & 12.4 & 45 \\
\hline SD & 1.6 & 2.2 & 1.1 & 3.8 & 1.9 & 5.0 & 1.9 & 2.5 & 12.0 \\
\hline
\end{tabular}

NYU = New York University; RWJ = Robert Wood Johnson; UCLA = University of California Los Angeles; UCSF = UC San Francisco.

ings are adhered to, can lower the chances that a patient may develop an aneurysm.

A study by Dutta-Bergman et al. assessed consumer evaluations of the trustworthiness of different sources of health care information on the Internet. ${ }^{16}$ Nearly half of the respondents revealed that they considered medical universities as among the top 3 most trusted sources of online patient education materials. Our study specifically assessed the readability of text downloaded from academic institutions, further underscoring the need to intervene and simplify these materials, given the number of people who are likely refer to these resources. Given the complex pathologies and anatomical terms typically associated with cerebrovascular conditions, this is especially important to consider. Previous studies on the readability of patient education materials for patients undergoing neurosurgical procedures, including those relevant to skull base tumors, have found similar results..$^{1-3,29}$

Future interventions aimed at improving the readability of patient education materials can have system-wide effects, given the ability of these resources to potentially lessen the need to treat preventable diseases across an array of medical subspecialties. Furthermore, this information can aid patients in better understanding the potential benefits and risks associated with various medical procedures, thereby increasing the likelihood that they will make informed decisions in the clinical setting (i.e., prior to any health intervention). ${ }^{18}$ There are legal implications to consider as well: a demonstrated lack of informed consent can serve as the basis for medical malpractice claims. Neurosurgeons are at high risk among their peers for being implicated in malpractice suits. ${ }^{12}$ By enabling patients to better understand their diagnoses and potential treat- ment options, interventions aimed at improving the readability of patient education materials may indirectly serve an important role in decreasing the frequency with which malpractice litigation occurs. However, it is important to note that these interventions cannot replace obtaining informed consent, and that physicians cannot make any assumptions regarding patient comprehension within the clinical setting in relation to these materials.

There are a number of ways to improve the readability of existing patient education resources. The use of simpler and more concise sentences and the elimination of lengthy, complex neuroanatomical terms can serve as methods of improvement. Avoiding the frequent use of polysyllabic words and complex sentence structures is also essential. Finally, the incorporation of flow charts, graphs, and other illustrations as visual aids to these resources can influence the comprehension of textual information. ${ }^{29}$

\section{Limitations of the Study}

We recognize that although readability is an important part of comprehension and functional health literacy, other factors including socioeconomic status, race, education, and income can all contribute. Readability, however, serves as an important and feasible area for future direct intervention. Likewise, although this study incorporates patient education materials published by a number of major academic institutions, published materials from other resources (including MEDLINE, Wikipedia, and WebMD) may influence patient decision making in the clinical setting, and should be considered for analysis in future studies. Finally, other factors, including the presentation and the layout of textual information, can influence under- 
standing. Therefore, simply increasing the readability of existing materials may not suffice on its own.

\section{Conclusions}

Brain aneurysm-related patient education materials published by major academic institutions are written at a reading level significantly higher than that recommended by the NIH and AMA. This may adversely affect comprehension, preventing patients from fully understanding the scope of their existing condition(s). Future health literacy interventions should focus on improving the readability of patient education materials on brain aneurysms, given the increasing rate at which these lesions are being diagnosed.

\section{References}

1. Agarwal N, Feghhi DP, Gupta R, Hansberry DR, Quinn JC, Heary RF, et al: A comparative analysis of minimally invasive and open spine surgery patient education resources. J Neurosurg Spine 21:468-474, 2014

2. Agarwal N, Hansberry DR, Sabourin V, Tomei KL, Prestigiacomo CJ: A comparative analysis of the quality of patient education materials from medical specialties. JAMA Intern Med 173:1257-1259, 2013

3. Agarwal N, Sarris C, Hansberry DR, Lin MJ, Barrese JC, Prestigiacomo CJ: Quality of patient education materials for rehabilitation after neurological surgery. NeuroRehabilitation 32:817-821, 2013

4. Agarwal N, Shah K, Stone JG, Ricks CB, Friedlander RM: Educational resources "over the head" of neurosurgical patients: the economic impact of inadequate health literacy. World Neurosurg 84:1223-1226, 2015

5. Ajiboye N, Chalouhi N, Starke RM, Zanaty M, Bell R: Unruptured cerebral aneurysms: evaluation and management. ScientificWorldJournal 2015:954954, 2015

6. Badarudeen S, Sabharwal S: Assessing readability of patient education materials: current role in orthopaedics. Clin Orthop Relat Res 468:2572-2580, 2010

7. Baker DW, Parker RM, Williams MV, Clark WS, Nurss J: The relationship of patient reading ability to self-reported health and use of health services. Am J Public Health 87:1027-1030, 1997

8. Bass L: Health literacy: implications for teaching the adult patient. J Infus Nurs 28:15-22, 2005

9. Berkman ND, Sheridan SL, Donahue KE, Halpern DJ, Crotty K: Low health literacy and health outcomes: an updated systematic review. Ann Intern Med 155:97-107, 2011

10. Caylor JS, Sticht TG, Fox LC, Ford JP: Methodologies for Determining Reading Requirements of Military Occupational Specialties. Alexandria, VA: Human Resources Research Organization, 1973 (http://eric.ed.gov/?id=ED074343) [Accessed August 3, 2016]

11. Cherla DV, Sanghvi S, Agarwal N, Eloy JA, Couldwell WT, Liu JK: Analysis of internet-based patient education materials related to pituitary tumors. Endocr Pract 20:1044-1050, 2014

12. Chi JH: Neurosurgery tops malpractice risk. Neurosurgery 69:N18-N20, 2011

13. Coleman M, Liau T: A computer readability formula designed for machine scoring. J Appl Psych 60:283-284, 1975

14. De Oliveira GS Jr, Jung M, Mccaffery KJ, McCarthy RJ, Wolf MS: Readability evaluation of Internet-based patient education materials related to the anesthesiology field. J Clin Anesth 27:401-405, 2015

15. Duren-Winfield V, Onsomu EO, Case DL, Pignone M, Miller D Jr: Health literacy and computer-assisted instruction: us- ability and patient preference. J Health Commun 20:491498, 2015

16. Dutta-Bergman M: Trusted online sources of health information: differences in demographics, health beliefs, and healthinformation orientation. J Med Internet Res 5:e21, 2003

17. Eloy JA, Li S, Kasabwala K, Agarwal N, Hansberry DR, Baredes S, et al: Readability assessment of patient education materials on major otolaryngology association websites. Otolaryngol Head Neck Surg 147:848-854, 2012

18. Fleisher L, Raivitch S, Miller SM, Partida Y, Martin-Boyan A, Soltoff C, et al: A Practical Guide to Informed Consent. (http://www.templehealth.org/ICTOOLKIT/html/ ictoolkitpage7.html) [Accessed June 22, 2016]

19. Fox S: The social life of health information, 2011. Pew Research Center. May 12, 2011. (http://www.pewinternet. org/2011/05/12/the-social-life-of-health-information-2011/) [Accessed June 22, 2016]

20. Freimuth VS: Assessing the readability of health education messages. Public Health Rep 94:568-570, 1979

21. Fry E: A readability formula that saves time. J Reading 11:513-578, 1968

22. Gunning R: The Technique of Clear Writing. New York: McGraw-Hill, 1952

23. Hansberry DR, Agarwal N, Baker SR: Health literacy and online educational resources: an opportunity to educate patients. AJR Am J Roentgenol 204:111-116, 2015

24. Hansberry DR, Agarwal N, Shah R, Schmitt PJ, Baredes S, Setzen M, et al: Analysis of the readability of patient education materials from surgical subspecialties. Laryngoscope 124:405-412, 2014

25. Huang G, Fang CH, Agarwal N, Bhagat N, Eloy JA, Langer PD: Assessment of online patient education materials from major ophthalmologic associations. JAMA Ophthalmol 133:449-454, 2015

26. Kincaid JP, Fishburne RP Jr, Rogers RL, Chissom BS: Derivation of New Readability Formulas (Automated Readability Index, Fog Count and Flesch Reading Ease Formula) for Navy Enlisted Personnel. Millington, TN: Chief of Naval Technical Training, 1975 (http://www.dtic.mil/dtic/ tr/fulltext/u2/a006655.pdf) [Accessed August 3, 2016]

27. Lee PP: Why literacy matters. Links between reading ability and health. Arch Ophthalmol 117:100-103, 1999

28. McLaughlin GH: SMOG grading-a new readability formula. J Reading 12:639-646, 1969

29. Misra P, Agarwal N, Kasabwala K, Hansberry DR, Setzen M, Eloy JA: Readability analysis of healthcare-oriented education resources from the American Academy of Facial Plastic and Reconstructive Surgery. Laryngoscope 123:90-96, 2013

30. Ogilvy CS, Chua MH, Fusco MR, Griessenauer CJ, Harrigan MR, Sonig A, et al: Validation of a system to predict recanalization after endovascular treatment of intracranial aneurysms. Neurosurgery 77:168-174, 2015

31. Patel SK, Gordon EJ, Wong CA, Grobman WA, Goucher H, Toledo P: Readability, content, and quality assessment of web-based patient education materials addressing neuraxial labor analgesia. Anesth Analg 121:1295-1300, 2015

32. Perrin A, Duggan M: Americans' Internet access: 2000 -2015. Pew Research Center. June 26, 2015. (http://www. pewinternet.org/2015/06/26/americans-internet-access -2000-2015/) [Accessed June 22, 2016]

33. Punia V, Dagar A, Agarwal N, He W, Hillen M: Comparison of neurological healthcare oriented educational resources for patients on the internet. J Clin Neurosci 21:2179-2183, 2014

34. Raygor AL: The Raygor readability estimate: a quick and easy way to determine difficulty, in Pearson PD (ed): Reading: Theory, Research, and Practice (26th Yearbook of the National Reading Conference). Clemson, SC: National Reading Conference, 1977 
35. Sanghvi S, Cherla DV, Shukla PA, Eloy JA: Readability assessment of internet-based patient education materials related to facial fractures. Laryngoscope 122:1943-1948, 2012

36. Sheppard ED, Hyde Z, Florence MN, McGwin G, Kirchner JS, Ponce BA: Improving the readability of online foot and ankle patient education materials. Foot Ankle Int 35:12821286, 2014

37. Sørensen K, Van den Broucke S, Fullam J, Doyle G, Pelikan J, Slonska Z, et al: Health literacy and public health: a systematic review and integration of definitions and models.

BMC Public Health 12:80, 2012

38. Walsh TM, Volsko TA: Readability assessment of internetbased consumer health information. Respir Care 53:1310 1315,2008

\section{Disclosures}

The authors report no conflict of interest concerning the materi- als or methods used in this study or the findings specified in this paper.

\section{Author Contributions}

Conception and design: Gupta. Acquisition of data: Gupta, Kim. Analysis and interpretation of data: Gupt, Kim. Drafting the article: Gupta, Patel. Critically revising the article: Ogilvy, Adeeb, Griessenauer, Moore, Patel. Reviewed submitted version of manuscript: Ogilvy, Adeeb, Griessenauer, Moore, Thomas Approved the final version of the manuscript on behalf of all authors: Ogilvy. Administrative/technical/material support: Adeeb, Griessenauer, Moore, Thomas. Study supervision: Ogilvy, Adeeb, Griessenauer, Moore, Thomas.

\section{Correspondence}

Christopher S. Ogilvy, Department of Surgery, Division of Neurosurgery, Beth Israel Deaconess Medical Center, Harvard Medical School, 110 Francis St., Boston, MA 02215-5501. email: cogilvy@bidmc.harvard.edu. 